\title{
Correction to: A configurative synthesis of evidence for fear in the criminal decision-making process
}

\section{Paul Gill ${ }^{1}$ - Lisa Tompson ${ }^{1} \cdot$ Zoe Marchment $^{1}$ - Florian Hetzel ${ }^{1}$. Sanaz Zolghadriha ${ }^{1} \cdot$ Aiden Sidebottom $^{1}$}

Published online: 29 October 2019

(c) Springer Nature Limited 2019

\section{Correction to: Security Journal https://doi.org/10.1057/s41284-019-00201-w}

In the original publication of the article, the Acknowledgement section was missed. The Acknowledgement section should read as:

Acknowledgements This research was funded by the Centre for Protection of National Infrastructure (CPNI).

The original article can be found online at https://doi.org/10.1057/s41284-019-00201-w.

\section{Paul Gill}

paul.gill@ucl.ac.uk

1 Department of Security and Crime Science, University College London, London, UK 